\title{
The PecT Repressor Coregulates Synthesis of Exopolysaccharides and Virulence Factors in Erwinia chrysanthemi
}

\author{
Guy Condemine, ${ }^{1}$ Arnaud Castillo, ${ }^{1}$ Fabrice Passeri, ${ }^{1}$ and Corine Enard ${ }^{2}$ \\ ${ }^{1}$ Laboratoire de Génétique Moléculaire des Microorganismes et des Interactions Cellulaires, UMR-CNRS \\ 5577, INSA Bat 406, 20 Av Einstein, 69621 Villeurbanne, France; 'Laboratoire de Pathologie Végétale, \\ INA-PG, 16 rue Claude Bernard, 75231 Paris Cedex 05, France \\ Accepted 7 October 1998.
}

Erwinia chrysanthemi 3937 synthesizes an exopolysaccharide (EPS) composed of rhamnose, galactose, and galacturonic acid. Fourteen transcriptional fusions in genes required for EPS synthesis, named eps, were obtained by Tn5-B21 mutagenesis. Eleven of them are clustered on the chromosome and are repressed by PecT, a regulator of pectate lyase synthesis. In addition, expression of these fusions is repressed by the catabolite regulatory protein, CRP, and induced in low osmolarity medium. The three other mutations are located in genes that are not regulated by pecT. A 13-kb DNA fragment containing pecTregulated eps genes has been cloned. All the genes identified on this fragment are transcribed in the same orientation and could form a large operon. The promoter region of this operon has been sequenced. It contains a JUMPstart sequence, a sequence required for the expression of polysaccharide-associated operons. E. chrysanthemi 3937 produces a systemic soft rot on its host Saintpaulia ionantha. An eps mutant was less efficient than the wild-type strain in initiating a maceration symptom, suggesting that production of EPS is required for the full expression of the E. chrysanthemi virulence.

Synthesis of exopolysaccharides (EPS) is an important factor for many plant-pathogenic bacteria to provoke normal disease symptoms such as water-soaking or wilting. Their role has been well documented in bacteria such as Ralstonia solanacearum, Erwinia stewartii (Pantoea stewartii subsp. stewartii), and Erwinia amylovora (Denny 1995; Leigh and Coplin 1992). Regulation of their synthesis is often complex and responds to numerous environmental and specific signals. $R$. solanacearum causes a lethal wilting on many plant species. Production of an acidic, glucosamine-rich EPS is one of the main causes of its pathogenicity (Denny and Baek 1991). Besides a specific regulation by two two-component regulatory systems (VsrA/D and $\mathrm{VsrB} / \mathrm{C}$ ) and the activator XpsR (Huang et al. 1995), synthesis of this EPS is coregulated with

Corresponding author: G. Condemine

E-mail: condemin@insa.insa-lyon.fr

Nucleotide and/or amino acid sequence data have been submitted to the EMBL data base as accession no. AJ009561. that of other virulence factors such as endopolygalacturonase A, a pectin methylesterase, and an endoglucanase, through a regulatory cascade that involves the products of the $p h c A, B$, $R$, and $S$ genes (Brumbley et al. 1993; Clough et al. 1997).

EPS are the main virulence factors of $E$. stewartii and $E$. amylovora. E. stewartii produces stewartan, an extracellular heteropolysaccharide that contributes to the water-soaking symptoms observed in Stewart's wilt of corn. E. amylovora synthesizes two types of EPS, levan and amylovoran. In these two bacteria, regulation of EPS synthesis is very similar to that described for the regulation of colanic acid capsule synthesis in Escherichia coli, where the cps genes are activated by $r \operatorname{cs} A$ and the $r \operatorname{cs} B$ - $r \operatorname{cs} C$ couple. The quantity of the regulatory protein RcsA in E. coli and E. amylovora is controlled by the Lon protease. RcsB is the regulatory part of a twocomponent system that is negatively regulated by the membrane sensor RcsC on the level of phosphorylation (Gottesman 1995). In E. stewartii, a negative regulator, EsaR, mediates quorum-sensing control of stewartan synthesis (Beck von Bodman and Farrand 1995; Beck von Bodman et al. 1998). Nothing has been described regarding the possible role of EPS in the pathogenicity of pectinolytic Erwinias.

Production of plant cell wall-degrading enzymes, mostly pectinases, is the main cause of $E$. chrysanthemi pathogenicity. The synthesis of virulence factors is controlled in E. chrysanthemi by three main specific repressors: KdgR, PecS, and PecT. KdgR regulates the genes of the pectin degradation pathway and the genes allowing the secretion of pectinases in response to the presence of pectin metabolism products (Condemine and Robert-Baudouy 1987b; Nasser et al. 1994). PecS is a repressor of the pectate lyase genes, of the secretion pathway genes, and of genes required for the synthesis of a blue pigment (Reverchon et al. 1994). The signal to which it responds is, for the moment, unknown. A pecT mutant synthesizes pectate lyases at a higher level but exhibits additional phenotypes: it flocculates when grown in liquid minimal medium, indicative of a modification of cell surface properties, and the colonies have a mucoid aspect on minimal medium agar plate (Surgey et al. 1996). This is a typical sign of an increased synthesis of EPS. An analysis of the EPS produced by E. chrysanthemi 3937 showed that it is composed of L-rhamnose, D-galactose, and galacturonic acid (4:1:1) (R. Montgomery, personal communication). To establish the coregulation of virulence factors and EPS synthesis genes in $E$. 
chrysanthemi, we have studied the regulation of EPS synthesis by constructing gene fusions in the eps genes, involved in EPS synthesis. We have shown that most of the eps genes are repressed by PecT and the catabolite regulatory protein, CRP. Moreover, we have studied the pathogenicity of an EPSdeficient strain.

\section{RESULTS}

\section{Isolation of EPS-deficient mutants.}

On $0.2 \%$ glycerol-containing minimal medium agar plates E. chrysanthemi pecT mutants have a mucoid aspect that is more pronounced when the medium is supplemented with $1 \%$ glucose. The EPS overproducing pecT mutant A2148 was mutagenized with the transposon Tn5-B21. This transposon, which encodes tetracycline resistance, also contains at one of its extremities the lac $Z$ gene deleted of its regulatory regions. This allows the construction of a transcriptional fusion with the gene in which the transposon is inserted when it is in the proper orientation. Nonmucoid mutants were obtained at a frequency of $1 \%$. Of the 34 nonmucoid mutants obtained, 14 had a $\mathrm{Lac}^{+}$phenotype, indicating that the transposon was inserted in the proper orientation to give a transcriptional fusion. When the insertion present in these 14 strains was transduced into a wild-type background (strain A350), the transductants were EPS ${ }^{-}$. The expression of the fusions in the wild-type and pecT backgrounds was compared. Eleven fusions had a higher expression in the pecT background, while three (eps-21, eps22, and eps-23) were expressed at the same level in both backgrounds (data not shown). A strain containing a pecTregulated insertion (strain A2575) was retained for further investigation.

The transposon inserted in strain A2575 was mapped between the gal-1 and ade-3 markers on the E. chrysanthemi chromosomal map (Hugouvieux-Cotte-Pattat et al. 1989). pecT mutants flocculate when grown in liquid minimal medium. EPS ${ }^{-}$mutants retained this capacity, indicating that overproduction of EPS is not the cause of flocculation. The level of pectate lyase synthesis was not changed in EPS ${ }^{-}$mutants (data not shown).

\section{Cloning of the EPS synthesis genes and construction of a uidA fusion.}

Tn5-B21 insertions are not very stable in E. chrysanthemi and often give secondary transpositions. We constructed a stable gene fusion by inserting a uidA-kan cassette into the eps locus mutated in strain A2575. The chromosomal DNA of strain A2575 was extracted, digested with the enzyme NsiI, which does not cut Tn5-B21, and ligated into PstI-digested pBluescript. Selection of $\operatorname{Tet}^{\mathrm{r}}$ clones allowed the isolation of a plasmid containing a 11.2-kb DNA fragment, including $8 \mathrm{~kb}$ of Tn5-B21 DNA. The remainder, $3.2 \mathrm{~kb}$, corresponded to chromosomal DNA adjacent to the point of insertion. A rough restriction map of this plasmid indicated that it contained a unique $B g l \mathrm{II}$ site $1.4 \mathrm{~kb}$ upstream of the lac $Z$ extremity of Tn5-B21. A uidA-kan cassette was inserted into this site in both orientations. The insertion that created a transcriptional fusion with uidA (Fig. 1) was recombined into the E. chrysanthemi chromosome. The recombinant strain (A2952) was not mucoid on $1 \%$ glucose plates, indicating that the $B g l \mathrm{II}$ site is inside an EPS synthesis gene. The $\mathrm{Kan}^{\mathrm{r}}$ insertion of A2952 was transduced into the $14 \mathrm{Tn} 5-B 21$ insertions and the percentage of $\mathrm{Tet}^{\mathrm{s}}$ transductants was determined. The uidA-kan insertion strongly cotransduced $(>90 \%)$ with the 11 pecTregulated Tn5-B21 insertions but not with the three non pecTregulated insertions, indicating that the 11 pecT-regulated insertions are clustered on the chromosome.

EPS synthesis genes are usually grouped in a large operon. To clone additional eps genes, we digested the chromosomal DNA of strain A2952 by the restriction enzymes SalI or HindIII, ligated the fragments in pBluescript, and selected $\mathrm{Kan}^{\mathrm{r}}$ clones. Analysis of these plasmids showed that we have cloned $6.5 \mathrm{~kb}$ of DNA located upstream of the point of insertion of the uidA-kan cassette and $7 \mathrm{~kb}$ downstream. Partial sequencing was performed, using a number of evenly spaced restriction sites (Fig. 1). The six open reading frames (ORFs) deduced from sequenced fragments from the SalI1, PstI1, NsiI2, BglII2, Bam HI2, and PstI2 sites showed homology with genes present in data bases (Table 1). Five of them, oriented in the same direction, had homology with EPS synthesis genes present in various bacteria; using the nomenclature recommended in Reeves et al. (1996): wza, wzc, weaP, rmlB, and $r m l A$ (Fig. 1). The gene located upstream of $w z a$, ORF1, is in the opposite orientation, and does not present homology with known EPS synthesis genes. Sequencing performed from the HindIII site did not yield significant homology with any sequence present in data bases.

\section{Regulation of the EPS synthesis genes.}

The insertion of strain A2952 is in the weaP gene. This weaP::uidA fusion was used to study the factors regulating

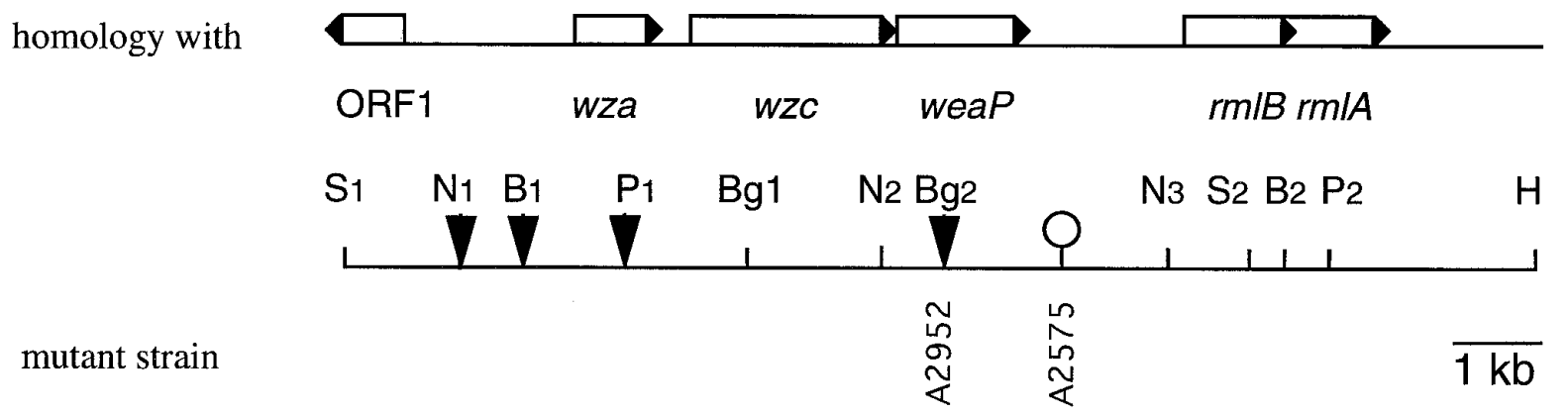

Fig. 1. Physical and genetic map of a 13-kb DNA fragment containing exopolysaccharide (EPS) synthesis genes. Bottom line indicates position of restriction sites. S: SalI, N: NsiI, B: BamHI, P: PstI, Bg: BglII, H: HindIII. Position of insertion of Tn5-B21 in strain A2575, indicated by an open circle. Position of insertion of uidA-kan cassettes, indicated by a black triangle. Position of genes deduced from partial DNA sequencing, indicated on top line. 
EPS synthesis. Anaerobiosis or high osmolarity did not modify expression of the fusion. Growth in a medium of low osmolarity $(50 \mathrm{mOsm})$ induced threefold greater expression (Table 2). Incubation of the plates at $37^{\circ} \mathrm{C}$ increased EPS production and this effect was confirmed by assay of the fusion expression. Addition of leucine, which prevents flocculation due to the pecT mutation, did not modify the expression of the weaP gene. The effect of various carbon sources as potential inducers was tested. Polygalacturonate, glucuronate, plant extract, galacturonate, and galactose (the last two sugars are components of E. chrysanthemi 3937 EPS) had no effect. In contrast, addition of rhamnose (another sugar present in EPS) or glucose at high concentration $(1 \%)$ increased expression of the fusion 1.5- to twofold (Table 2).

The effect of the genes regulating pectinase synthesis was tested. As expected from the above results, the expression of the fusion was increased (threefold) in a pecT mutant (Table 2). Culture of the pecT weaP::uidA strain with glucose as the carbon source led to a further increase, suggesting that PecT is not the regulator that senses glucose concentration. Induction by low osmolarity was higher (sixfold) in a pecT than in the wild-type background. In a pecS mutant, expression of the eps gene was lower, whatever the culture conditions. Expression of the fusion was not significantly modified in a $k d g R$ background. To test if the glucose effect could be mediated by the catabolite regulatory protein, CRP, the fusion was introduced into a crp background. Its expression increased more than 10fold (Table 2). Thus, CRP is a repressor of EPS synthesis. This effect was cumulative with that of the pecT mutation (Table 2). Recently, Missiakas and Raina (1997) have shown that the periplasmic stress caused by a $d s b A$ mutation (no formation of disulfide bonds in periplasmic proteins) was able to induce production of colanic acid capsular polysaccharide in $E$. coli. In E. chrysanthemi, a $d s b A$ mutation had a similar effect on EPS gene expression (Table 2).

\section{Analysis of the eps gene regulatory region.}

A uidA-kan cassette extracted from plasmid pUIDK3 was inserted into the NsiI1 and BamHI1 sites present upstream of $w z a$ and in the PstI1 site present in wza (Fig. 1). This cassette was constructed so that transcription occurs from the kanamycin resistance gene into the downstream DNA. Insertion into the PstI1 site with the orientation of $w z a$ gave rise to an $\mathrm{EPS}^{-}$ mutant in which expression of $\beta$-glucuronidase was regulated by pecT and crp (data not shown). Insertion into the BamHI1 site in the orientation of $w z a$ gave an $\mathrm{EPS}^{+}$strain and expression of $\beta$-glucuronidase was regulated by pecT and crp. However, the cassette inserted in the opposite orientation gave an
EPS $^{-}$strain. When the cassette was inserted into the NsiI1 site, in any orientation, the strain was EPS ${ }^{+}$and did not express $\beta$-glucuronidase. Thus, the BamHI1 site is located between the transcription and the translation start sites of the EPS biosynthesis operon while the NsiI site is located upstream of the promoter. The 580-bp NsiI-BamHI DNA fragment was sequenced (Fig. 2). A putative promoter with a -35 region containing 4 of the 6 nucleotides of the consensus (TTGTCT) at position 228 to 233 and a -10 region containing 4 of the 6 nucleotides of the consensus (TTTACT) at position 252 to 257 was identified. A putative CRP-box could be found from position 267 to 285 . A JUMPstart sequence is located between nucleotides 402 and 439 (Fig. 2). JUMPstart sequences are 39 nucleotide conserved sequences identified first in the $5^{\prime}$ region of polysaccharide biosynthesis operons but

Table 2. Expression of a weaP::uidA fusion in various growth conditions and in various backgrounds

\begin{tabular}{llc}
\hline $\begin{array}{l}\text { Additional } \\
\text { mutation }\end{array}$ & \multicolumn{1}{c}{ Growth condition } & $\begin{array}{c}\text { a-glucuronidase } \\
\text { specific activity }\end{array}$ \\
\hline- & Glycerol & 80 \\
- & Glycerol (anaerobiosis) & 71 \\
- & Glycerol + 0.3M NaCl & 83 \\
- & Glycerol (low osmolarity) & 266 \\
- & Glycerol (37 C) & 126 \\
- & Glycerol + leucine & 74 \\
- & Glycerol + PGA & 83 \\
- & Glycerol + plant extract & 75 \\
- & Glycerol + glucuronate & 75 \\
- & Glycerol + galacturonate & 64 \\
- & Glycerol + galactose & 75 \\
- & Glycerol + rhamnose & 140 \\
- & Glucose (0.2\%) & 129 \\
- & Glucose (1\%) & 156 \\
pecT & Glycerol & 238 \\
& Glucose (1\%) & 391 \\
& Glycerol (low osmolarity) & 1264 \\
$k d g R$ & Glycerol & 108 \\
pecS & Glycerol & 54 \\
& Glucose (1\%) & 43 \\
crp & Glucose (1\%) & 930 \\
crp pecT & Glucose (1\%) & 1475 \\
- & Glucose (1\%) & 453 \\
\hline
\end{tabular}

a The bacteria were grown in M63 medium at $30^{\circ} \mathrm{C}$ unless overwise stated to an $\mathrm{OD}_{600}$ of 1.2 to 1.5 . Anaerobic cultures were realized by overlaying the culture medium with paraffin oil. Fumarate $(0.25 \%)$ was added as an electron acceptor. High osmolarity was obtained by adding $0.3 \mathrm{M} \mathrm{NaCl}$ to $\mathrm{M} 63$ medium. Low osmolarity medium was fivefold diluted M63 medium.

${ }^{\mathrm{b}}$ Results presented are the average of at least three independent assays. Standard deviation was less than $20 \%$. Activity is expressed as nmole of $p$-nitrophenol formed per min per mg of bacterial dry weight.

Table 1. Homology between Erwinia chrysanthemi exopolysaccharide (EPS) synthesis proteins and proteins present in data bases

\begin{tabular}{llll}
\hline Sequence from site & \multicolumn{1}{c}{ Homology $^{\mathbf{a}}$} & Gene $^{\mathbf{c}}$ & \multicolumn{1}{c}{ Reference $^{-}$} \\
\hline SalI1 & Klebsiella pneumoniae ORF19 (79\% over 44 amino acids [aa]) & & Arakawa et al. 1995 \\
PstI1 & E. amylovora AsmH (78\% over 65 aa) & wza & Bugert and Geider 1995 \\
NsiI2 & E. amylovora AsmA (70\% over 51 aa) & wzc & Bugert and Geider 1995 \\
BglII2 & Salmonella typhimurium LT2 Rfb (46\% over 64 aa) & wbaP & Jiang et al. 1991 \\
BamHI2 & Escherichia coli RffG (72\% over 36 aa) & rmlB & Marolda and Valvano 1995 \\
PstI2 & E. coli RffH (84\% over 49 aa) & rmlA & Marolda and Valvano 1995 \\
\hline
\end{tabular}

${ }^{a}$ The sites are those shown in Figure 1.

${ }^{\mathrm{b}}$ The proteins deduced from the sequence were compared with those contained in data bases, by the BLAST algorithm. The best homology is presented. The percentage of identity is indicated in parentheses.

${ }^{c}$ Name of the corresponding gene according to the Reeves et al. (1996) gene nomenclature. 
that can be found in front of other operons (Bailey et al. 1997; Hobbs and Reeves 1994).

\section{Pathogenicity of an EPS ${ }^{-}$mutant.}

When potted saintpaulia plants were inoculated with bacterial suspensions containing 3 to $5 \times 10^{8} \mathrm{CFU}$ per $\mathrm{ml}$, no significant difference was observed between the wild-type strain 3937 and the EPS $^{-}$mutant A3165 during the course of infection (data not shown). When the plants were infected with an inoculum containing 10 times fewer bacteria, similar symptoms were observed with both strains during the first week: about three-fourths of the plants expressed no symptoms. A difference appeared after 2 weeks (Fig. 3). A majority of the A3165-infected plants exhibited no symptom while systemic maceration appeared among plants infected with the wild-type strain. After 3 weeks, the main symptom observed with the EPS $^{-}$mutant was a patch of maceration whereas a majority of the plants infected with the wild-type strain showed a completely macerated, inoculated leaf. Finally, after 5 weeks, more than one-third of the plants inoculated with the EPS mutant showed only a patch of maceration that remained localized at the site of inoculation and had dried out. In conclusion, when the inoculum was low, the EPS $^{-}$mutant was not as efficient as the wild-type strain in initiating maceration and was unable to induce a systemic soft-rot symptom.

\section{DISCUSSION}

The high efficiency of $E$. chrysanthemi pectate lyases in macerating plant tissue has led research to focus on these enzymes and on the regulation of their synthesis, and to neglect the identification of other factors that could be important for disease development. The strategy to identify such factors has been to look for pgi (polygalacturonate induced) genes (Beaulieu and Van Gijsegem 1990; Hugouvieux-Cotte-Pattat and Robert-Baudouy 1989). However, the pgi genes characterized so far are mostly pectinase genes (Shevchik and Hugouvieux-Cotte-Pattat 1997; Shevchik et al. 1997). Another approach can be undertaken to find factors regulated by the genes controlling pectate lyases synthesis, pecS and pecT. The mucoid aspect of pecT mutants raised the possibility that PecT could regulate EPS synthesis. We show in this paper that most of the genes involved in EPS synthesis belong to the pecT regulon and that EPS production contributes to the full virulence of E. chrysanthemi.

The majority of the fusions isolated in genes required for EPS synthesis are regulated by PecT. These fusions are all localized in the same region of the chromosome, suggesting the presence of an EPS biosynthesis gene cluster. Sequence data show that the genes identified in this region, which present homology with genes involved in EPS synthesis of other bacteria, are transcribed in the same orientation. A JUMPstart sequence is present in the regulatory region of the first gene of this cluster. The JUMPstart sequences are present in $5^{\prime}$ untranslated part of EPS synthesis operon mRNAs. They contain the ops element, which recruits $\mathrm{RfaH}$, which increases the processivity of RNA polymerase and allows transcription to occur over a long distance (Bailey et al. 1997). These data led to the speculation that E. chrysanthemi EPS synthesis genes are grouped in an operon larger than $10 \mathrm{~kb}$. Such an organization has often been reported for EPS synthesis genes. The $E$. amylovora ams genes are grouped in a 16-kb operon (Bugert and Geider 1995) and the K. pneumoniae K2 cps gene cluster produces a transcript larger than $14 \mathrm{~kb}$ (Wacharotayankun et al. 1992). The genes identified by partial sequencing show homology with the genes wza, wzc, wbaP, rmlA, and $r m l B$.

$$
\begin{array}{lr}
\text { TGCATTATATGCCAAATAGCGTGTCGCGCGGGAAATAGCCCATCCTCTGGCTATTTAA } & 60 \\
\text { Nsil } & \\
\text { TAAGCTCATTAATGCGTAACAAAATTATATATGAAAATGAAATATTTATTAAGATGTC } & 120 \\
\text { TCTGATATATATAACTGTTTGTTTTTAATGATAAAAATATCTTGCTCATAAGAGAAAC } & 180 \\
\text { TGCATGGAATGTTAGTATTTTTCGAAAAAAAACACCAGGAAGATATTTTCTTGTTATA } & 240 \\
\text { AGCAAATATTTTTACTACTCTCCGGTGTGGCGATATTGACATATCTTTAAAAATATTTA } & 300 \\
\text { TGTGANNNNNTCACA } & 360 \\
\text { ATTCGAAACTTTAGTGTCGTTAATGTTTTGCAAGCCATTTTTACGAGTCAGTTATGACG } & 300 \\
\text { AGTCACAGCAATAGCTGGGCGAGTCTGAAACGAAAACGGGACAGCGAGTTGGTAGCTACG } & 420 \\
\text { MASYRYAYTGGTAGCTGWR } & \\
\text { AGCCAAGGGCGGTAGCGTACCTGATGCGATTCACCCGACAGCCGCAAGCGGCGTTTCAGA } & 480 \\
\text { CCCAGCCCTCCAGGACGTTGAAACCGTTCAGCCACCGGTATTCAGGCCTTCCGCCTGTTG } & 540 \\
\text { TTTGCCGATGAGCGAAGACGGAAACGATGTCAACGGATCC } & 580
\end{array}
$$

Fig. 2. Sequence of the 580-bp NsiI1-BamHI1 DNA fragment containing the possible promoter region of the exopolysaccharide (EPS) biosynthesis operon. Potential promoter is underlined. CRP-box is boxed. JUMPstart sequence is shaded in gray. The consensus of the CRP-box and that of the JUMPstart sequence (Hobbs and Reeves 1994) are indicated under the sequence (M, A, or C; Y, C; or T; R, G, or A; W, T, or A). This sequence will appear in the EMBL data bases under the accession number AJ009561. 
$w z a$ encodes an outer membrane lipoprotein of unknown function. $w z c$ encodes a protein that could have an autophosphorylating protein tyrosine kinase activity (Grangeasse et al. 1997). These two genes are always clustered with a third gene, $w z b$, that encodes a phosphatase (Reeves et al. 1996). This gene has not yet been found in E. chrysanthemi. S. typhimurium wbaP encodes an enzyme that transfers galactose1-phosphate to undecaprenyl-phosphate. E. chrysanthemi weaP shows only $45 \%$ homology with wba. Thus, we cannot conclude that these two genes encode proteins with the same function. The genes $r m l A$ and $r m l B$ are involved in the synthesis of dTDP-rhamnose from glucose (Köplin et al. 1993). The sequencing of the whole cluster will be necessary to identify all the genes required for EPS synthesis in E. chrysanthemi.

The regulation of E. chrysanthemi EPS synthesis is complex. Two negative regulators have been identified: pecT and crp. While a pecT mutation increases EPS production, a mutant overproducing PecT synthesizes less EPS than the wildtype strain (Castillo and Reverchon 1997), suggesting a direct role of PecT in repression. While pecT links EPS production with that of pectate lyases, crp has opposite effects on EPS and pectate lyases synthesis since a $\mathrm{crp}$ mutant does not synthesize any pectate lyase (Reverchon et al. 1997). Identification of a potential CRP-binding box downstream of the wza putative transcription start could explain the repressor role of crp: binding of CRP at this position would inhibit fixation of the RNA polymerase (Kolb et al. 1993). The increased EPS synthesis in a low osmolarity medium may help the bacteria to retain salts and nutrients in this less favorable growth condition, which could be encountered by the bacteria in the soil or in plant tissue.

Infection of Saintpaulia ionantha with the wild-type strain 3937 never gives $100 \%$ of systemic maceration but a part of the infection stops at the stage of one macerated leaf. E. chrysanthemi EPS $^{-}$mutants have a reduced virulence on saintpaulia. With a low inoculum, not only was systemic maceration never observed but also, after 5 weeks, some plants showed no symptoms or a dried-out maceration patch at the site of inoculation. Appearance of the symptoms seems delayed. Two hypotheses can be proposed on the role of EPS in the infection process: (i) EPS itself could be a virulence factor, like stewartan and amylovoran, blocking xylem vessels;
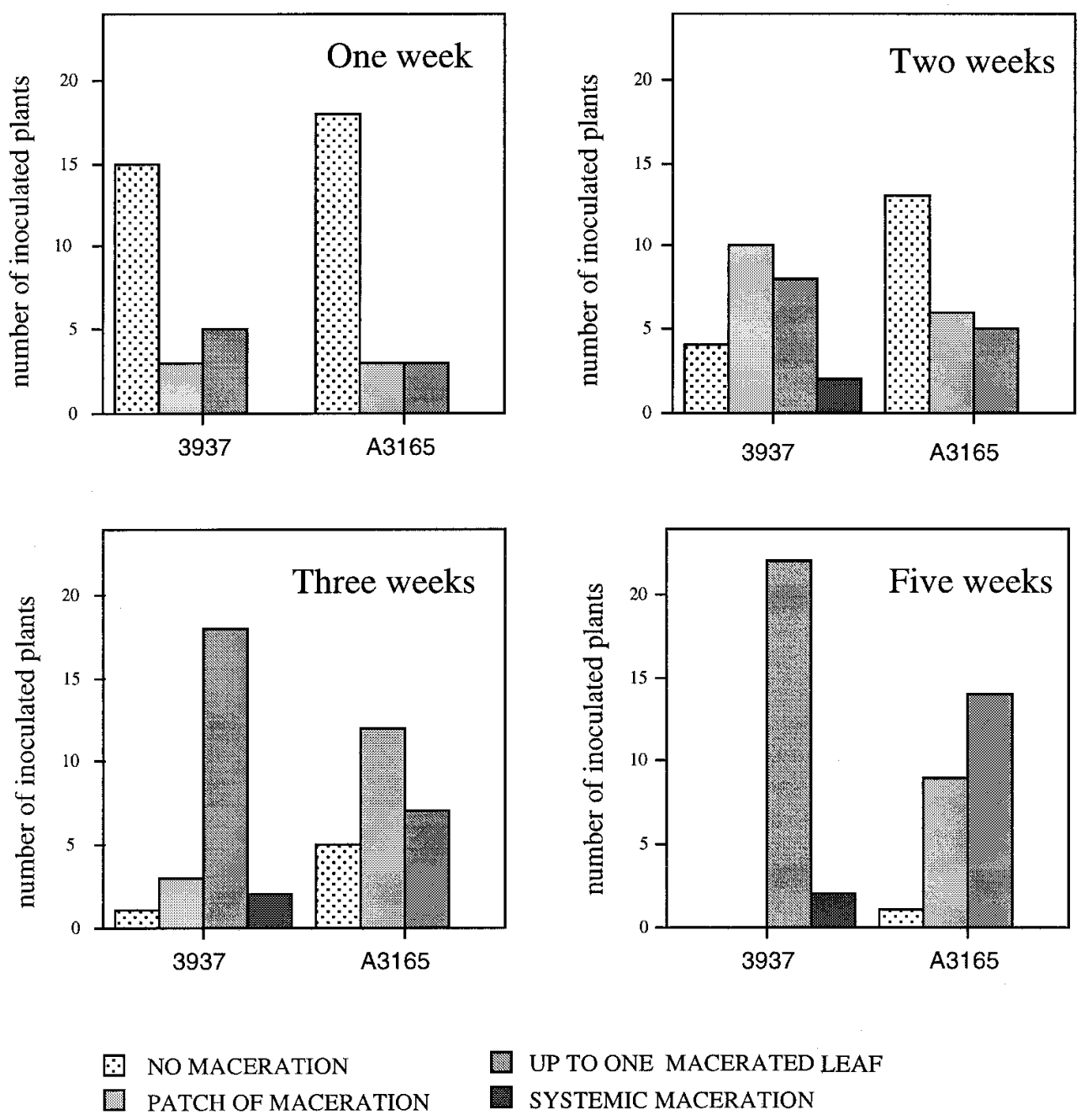

Fig. 3. Distribution of responses given by the EPS ${ }^{-}$mutant strain A3165 and the wild-type strain 3937 on African violets. Each strain was inoculated to 24 plants as described in the Materials and Methods. 
(ii) production of EPS could protect E. chrysanthemi and help it to survive in the soil or in the plant during the first steps of infection by creating a favorable environment. The delay before appearance of the first symptoms could correspond to the time required for the mutants to multiply in the less protected in planta condition due to the absence of EPS. The plant defense mechanisms could more easily kill the bacteria during this lag time. While amylovoran is produced by all the strains of E. amylovora, EPS produced by various E. chrysanthemi strains have a different composition (Yang et al. 1994, 1996), suggesting that the type of molecule produced is not of importance for this bacteria. Thus, the role of EPS may be to protect E. chrysanthemi cells in the plant. However, the coordinate synthesis of EPS and other virulence factors and the reduced virulence of $\mathrm{EPS}^{-}$mutants suggest that EPS is an authentic virulence factor in E. chrysanthemi.

\section{MATERIALS AND METHODS}

\section{Bacterial strains, plasmids, and culture conditions.}

Bacterial strains and plasmids used in this study are described in Table 3. E. chrysanthemi and E. coli cells were grown at 30 and $37^{\circ} \mathrm{C}$, respectively, in Luria broth medium or M63 minimal medium (Miller 1972) supplemented with a carbon source ( $0.2 \%$; except PGA [polygalacturonate], $0.4 \%$ ) and, when required, with amino acids $(40 \mu \mathrm{g} / \mathrm{ml})$ and the following antibiotics at the concentrations indicated: ampicillin, $100 \mu \mathrm{g} / \mathrm{ml}$; kanamycin, $50 \mu \mathrm{g} / \mathrm{ml}$; chloramphenicol, $20 \mu \mathrm{g} / \mathrm{ml}$; and tetracycline, $20 \mu \mathrm{g} / \mathrm{ml}$. M63 diluted fivefold was used as a low osmolarity medium. Production of EPS by E. chrysanthemi strains was tested on $1 \%$ glucose-containing minimal medium plates.

\section{Genetics techniques.}

Transduction with phage $\phi E C 2$ was done as described (Resibois et al. 1984). Gene mapping on the chromosome was performed by conjugation with pULB110 as previously re- ported (Hugouvieux-Cotte-Pattat and Robert-Baudouy 1989). Mutagenesis with transposon Tn5-B21 was performed by mixing $0.2 \mathrm{ml}$ of an overnight culture of strain S171/pSUP102-Tn5-B21 with $0.2 \mathrm{ml}$ of an overnight culture of the E. chrysanthemi recipient cell on an M63 agar plate. After $5 \mathrm{~h}$ at $30^{\circ} \mathrm{C}$, cells resuspended in $1 \mathrm{ml}$ of M63 medium and dilutions were spread on glucose-plus-tetracycline plates. Marker exchange recombinations were obtained after growth in a low-phosphate-concentration medium as described (Roeder and Collmer 1985).

\section{Enzyme assays.}

$\beta$-Glucuronidase assays were performed with toluenized cells grown to exponential phase with $p$-nitrophenyl- $\beta$-Dglucuronate as the substrate (Novel et al. 1974). $\beta$ Galactosidase assays were performed with toluenized cells grown to exponential phase with $o$-nitrophenyl- $\beta$-D-galactose as the substrate (Miller 1972). Pectate lyase activity was assayed on culture supernatant as described (Moran and Starr 1969).

\section{Recombinant DNA techniques.}

E. chrysanthemi chromosomal DNA was prepared according to Ausubel et al. (1987). Preparations of plasmid DNA, restriction digestions, ligations, DNA electrophoresis, transformations, and electroporations were carried out as described by Sambrook et al. (1989). Nucleotide sequence analysis was performed by the chain termination method with doublestranded DNA templates, with the Pharmacia T7 sequencing kit (Pharmacia, Uppsala, Sweden). The uidA-kan cassette was extracted from plasmid pUIDK3 (Bardonnet and Blanco 1992).

\section{Pathogenicity tests.}

The plant assay was carried out on potted Saintpaulia ionantha cv. Blue rhapsody (African violets) as previously described by Expert and Toussaint (1985) except that each

Table 3. Bacterial strains, plasmids, and phage used in this study

\begin{tabular}{|c|c|c|}
\hline Designation & Description & Reference or source \\
\hline \multicolumn{3}{|l|}{ Strains } \\
\hline \multicolumn{3}{|c|}{ Erwinia chrysanthemi } \\
\hline $3937 \mathrm{c}$ & Wild type & Laboratory collection \\
\hline A350 & $\operatorname{lm} r T^{\mathrm{c}} \operatorname{lac} \mathrm{Z}$ & Hugouvieux-Cotte-Pattat and Robert-Baudouy 1985 \\
\hline A837 & $\operatorname{lmr} T^{\mathrm{c}} \operatorname{lac} Z \mathrm{kdg} R$ & Condemine and Robert-Baudouy 1987 a \\
\hline A1524 & $\operatorname{lm} r T^{\mathrm{c}}$ lacZ pecS::MudIIPR13 & Reverchon et al. 1994 \\
\hline A2174 & $\operatorname{lmr} T^{\mathfrak{c}}$ lacZ pecT::Cm & Surgey et al. 1996 \\
\hline A2507 & $\operatorname{lmr} T^{\mathrm{c}}$ lacZ crp $:: \mathrm{Cm}$ & Reverchon et al. 1997 \\
\hline A2575 & $\operatorname{lm} r T^{\mathrm{c}}$ lacZ eps: :Tn5-B21 & This work \\
\hline A2628 & $\operatorname{lm} r T^{\mathrm{c}}$ lacZ $d s b A:: \mathrm{Cm}$ & Laboratory collection \\
\hline A2952 & $\operatorname{lmr} T^{\mathrm{c}}$ lac $Z$ weaP $::$ uidA-kan & This work \\
\hline A 3165 & weaP :: uidA-kan & This work \\
\hline \multicolumn{3}{|c|}{ Escherichia coli } \\
\hline NM522 & $\begin{array}{l}\Delta(\text { lac-proAB }) \text { thi hsd-5 supE }\left(\mathrm{F}^{\prime} \text { proAB }\right. \\
\text { laclq lac } \mathrm{Z} \Delta \mathrm{M} 15)\end{array}$ & Stratagene, La Jolla, CA \\
\hline S17-1 & hsdR pro RP4-2 Tc::Mu Km::Tn7 & Simon et al. 1983 \\
\hline \multicolumn{3}{|l|}{ Plasmids } \\
\hline $\mathrm{pBS}$ & $\mathrm{Ap}^{\mathrm{r}} l a c Z^{\prime}$ & Stratagene \\
\hline pB21 & pSUP102::Tn5-B21 & Simon et al. 1989 \\
\hline pUIDK3 & Contains a uidA-kan cassette & Bardonnet and Blanco 1992 \\
\hline \multicolumn{3}{|l|}{ Phage } \\
\hline$\phi \mathrm{EC} 2$ & E. chrysanthemi generalized transducing phage & Resibois et al. 1984 \\
\hline
\end{tabular}


bacterial strain was tested on 24 plants and prepared as follows: Bacteria were cultivated in M63 minimal medium overnight from a fresh L-agar plate and diluted in M63 medium at a concentration of 3 to $5 \times 10^{8}$ or 3 to $5 \times 10^{7} \mathrm{CFU}$ per $\mathrm{ml}$ and $100 \mu \mathrm{l}$ was inoculated into a leaf wounded with a scalpel. Plants were maintained in a growth chamber at 27 to $30^{\circ} \mathrm{C}$ under high moisture conditions, with $16 \mathrm{~h}$ of illumination daily.

\section{ACKNOWLEDGMENTS}

We thank R. Montgomery for providing information on EPS structure, W. Nasser for technical assistance, S. Reverchon and N. CottePattat for critical reading of the manuscript, and J. Robert-Baudouy for her support. This study was supported by grants from the Centre National de la Recherche Scientifique, from the Action Concertée Coordonnée-Sciences du vivant 6 (ACC-SV6) no. 9506111 from the Ministère de l'Education, de l'Enseignement Supérieur, de la Recherche et de l'Insertion Professionnelle.

\section{LITERATURE CITED}

Arakawa, Y., Wacharotayankun, R., Nagatsuka, T., Ito, H., Kato, N., and Ohta, M. 1995. Genomic organization of the Klebsiella pneumoniae cps region responsible for serotype $\mathrm{K} 2$ capsular polysaccharide synthesis in the virulent strain Chedid. J. Bacteriol. 177:1788-1796.

Ausubel, F. M., Brent, R., Kingston, R. E., Moore, D. D., Seidman, J. G., Smith, J. A., and Struhl, K. 1987. Current Protocols in Molecular Biology. Wiley-Interscience, New York.

Bailey, M. J. A., Hughes, C., and Koronakis, V. 1997. RfaH and the ops element, components of a novel system controlling bacterial transcription elongation. Mol. Microbiol. 26:845-851.

Bardonnet, N., and Blanco, C. 1992. uidA antibiotic resistance cassettes for insertion mutagenesis, gene fusion and genetic constructions. FEMS Microbiol. Lett. 93:243-248.

Beaulieu, C., and Van Gijsegem, F. 1990. Identification of plantinducible genes in Erwinia chrysanthemi 3937. J. Bacteriol. 172: 1569-1575.

Beck von Bodman, S., and Farrand, S. K. 1995. Capsular polysaccharide biosynthesis and pathogenicity in Erwinia stewartii require induction by an $N$-acylhomoserine lactone autoinducer. J. Bacteriol. 177:50005008.

Beck von Bodman, S., Majerczak, D. R., and Coplin, D. L. 1998. A negative regulator mediates quorum-sensing control of exopolysaccharide production in Pantoea stewartii subsp. stewartii. Proc. Natl. Acad. Sci. USA 95:7687-7692.

Brumbley, S. M., Carney, B. F., and Denny, T. P. 1993. Phenotype conversion in Pseudomonas solanacearum due to spontaneous inactivation of PhcA, a putative LysR transcriptional regulator. J. Bacteriol. 175:5477-5487.

Bugert, P., and Geider, K. 1995. Molecular analysis of the ams operon required for exopolysaccharide synthesis of Erwinia amylovora. Mol. Microbiol. 15:917-933.

Castillo, A., and Reverchon, S. 1997. Characterization of the pecT control region from Erwinia chrysanthemi 3937. J. Bacteriol. 179:49094918.

Clough, S. J., Lee, K.-E., Schell, M. A., and Denny, T. P. 1997. A twocomponent system in Ralstonia (Pseudomonas) solanacearum modulates production of a PhcA-regulated virulence factor in response to 3hydroxypalmitic acid methyl ester. J. Bacteriol. 179:3639-3948.

Condemine, G., and Robert-Baudouy, J. 1987a. 2-keto-3-deoxygluconate transport system in Erwinia chrysanthemi. J. Bacteriol. 169: 1972-1978.

Condemine, G., and Robert-Baudouy, J. 1987b. Tn5 insertion in $k d g R$, a regulatory gene of the polygalacturonate pathway in Erwinia chrysanthemi. FEMS Microbiol. Lett. 42:39-46.

Denny, T. P. 1995. Involvement of bacterial polysaccharides in plant pathogenesis. Annu. Rev. Phytopathol. 33:173-197.

Denny, T. P., and Baek, S.-R. 1991. Genetic evidence that extracellular polysaccharide is a virulence factor of Pseudomonas solanacearum. Mol. Plant-Microbe Interact. 4:198-206.
Expert, D., and Toussaint, A. 1985. Bacteriocin-resistant mutants of Erwinia chrysanthemi: Possible involvement of iron acquisition in phytopathogenicity. J. Bacteriol. 163:221-227.

Gottesman, S. 1995. Regulation of capsule synthesis: Modification of a two component paradigm by an accessory unstable protein. Pages 253-262 in: Two-Component Signal Transduction. J. A. Hoch and T. J. Silhavy, eds. American Society for Microbiology, Washington, DC.

Grangeasse, C., Doublet, P., Vaganay, E., Vincent, C., Deléage, G., Duclos, B., and Cozzone, A. J. 1997. Characterization of a bacterial gene encoding an autophosphorylating protein tyrosine kinase. Gene 204: 259-265.

Hobbs, M., and Reeves, P. R. 1994. The JUMPstart sequence: A 39 bp element common to several polysaccharide gene clusters. Mol. Microbiol. 12:855-856.

Huang, J., Carney, B. F., Denny, T. P., Weissinger, A. K., and Schell, M. A. 1995. A complex network regulates expression of eps and other virulence genes of Pseudomonas solanacearum. J. Bacteriol. 177: 1259-1267.

Hugouvieux-Cotte-Pattat, N., Reverchon, S., and Robert-Baudouy, J. 1989. Expanded linkage map of Erwinia chrysanthemi strain 3937. Mol. Microbiol. 3:573-581.

Hugouvieux-Cotte-Pattat, N., and Robert-Baudouy, J. 1985. Lactose catabolism in Erwinia chrysanthemi. J. Bacteriol. 162:248-255.

Hugouvieux-Cotte-Pattat, N., and Robert-Baudouy, J. 1989. Isolation of Erwinia chrysanthemi mutants altered in pectinolytic enzyme production. Mol. Microbiol. 3:1587-1597.

Jiang, X.-M., Neal, B., Santiago, F., Lee, S. J., Romana, L. K., and Reeves, P. R. 1991. Structure and sequence of the $r f b$ (O antigen) gene cluster of Salmonella serovar typhimurium (strain LT2). Mol. Microbiol. 5:695-713.

Kolb, A., Busby, S., Buc, H., Garges, S., and Adhya, S. 1993. Transcriptional regulation by cAMP and its receptor protein. Annu. Rev. Biochem. 62:749-795.

Köplin, R., Wang, G., Hötte, B., Priefer, U. B., and Pühler, A. 1993. A 3.9-kb DNA region of Xanthomonas campestris pv. campestris that is necessary for lipopolysaccharide production encodes a set of enzymes involved in the synthesis of dTDP-rhamnose. J. Bacteriol. 175:77867792.

Leigh, J. A., and Coplin, D. L. 1992. Exopolysaccharides in plantbacterial interactions. Annu. Rev. Microbiol. 46:307-346.

Marolda, C. L., and Valvano, M. A. 1995. Genetic analysis of the dTDPrhamnose biosynthesis region of the Escherichia coli VW187 $(\mathrm{O} 7: \mathrm{K} 1) r f b$ gene cluster: Identification of functional homologs of $r f b B$ and $r f b A$ in the $r f f$ cluster and correct location of the $r r f E$ gene. J. Bacteriol. 177:5539-5546.

Miller, J. H. 1972. Experiments in Molecular Genetics. Cold Spring Harbor Laboratory, Cold Spring Harbor, NY.

Missiakas, D., and Raina, S. 1997. Signal transduction pathways in response to protein misfolding in the extracytoplasmic compartments of E. coli: Role of two new phosphoprotein phosphatases PrpA and PrpB. EMBO J. 16:1670-1685.

Moran, F., and Starr, M. P. 1969. Metabolic regulation of polygalacturonic acid trans-eliminase in Erwinia. Eur. J. Biochem. 11:291-295.

Nasser, W., Reverchon, S., Condemine, G., and Robert-Baudouy, J. 1994. Specific interactions of Erwinia chrysanthemi KdgR repressor with different operators of genes involved in pectinolysis. J. Mol. Biol. 236:427-440.

Novel, G., Didier-Fichet, M. L., and Stoeber, F. 1974. Inductibility of $\beta$ glucuronidase in wild-type and hexuronate-negative mutants of Escherichia coli $\mathrm{K}-12$. J. Bacteriol. 120:89-95.

Reeves, P. R., Hobbs, M., Valvano, M. A., Skurnik, M., Whitfield, C., Coplin, D., Kido, N., Klena, J., Maskell, D., Raetz, C. R. H., and Rick, P. D. 1996. Bacterial polysaccharide synthesis and gene nomenclature. Trends Microbiol. 4:495-503.

Resibois, A., Colet, M., Faelen, M., Schoonejans, E., and Toussaint, A. 1984. PhiEC2, a new generalised transducing phage of Erwinia chrysanthemi. Virology 137:102-112.

Reverchon, S., Expert, D., Robert-Baudouy, J., and Nasser, W. 1997. The cyclic AMP receptor protein is the main activator of the pectinolysis genes in Erwinia chrysanthemi. J. Bacteriol. 179:3500-3508.

Reverchon, S., Nasser, W., and Robert-Baudouy, J. 1994. pecS: A locus controlling pectinase, cellulase and blue pigment production in $\mathrm{Er}$ winia chrysanthemi. Mol. Microbiol. 11:1127-1139.

Roeder, D. L., and Collmer, A. 1985. Marker-exchange mutagenesis of 
pectate lyase isozyme gene in Erwinia chrysanthemi. J. Bacteriol. 164:51-56.

Sambrook, J., Fritsch, E. F., and Maniatis, T. A. 1989. Molecular Cloning: A Laboratory Manual. 2nd ed. Cold Spring Harbor Laboratory, Cold Spring Harbor, NY.

Shevchik, V. E., and Hugouvieux-Cotte-Pattat, N. 1997. Identification of a bacterial pectin acetyl esterase in Erwinia chrysanthemi. Mol. Microbiol. 24:1285-1301.

Shevchik, V. E., Robert-Baudouy, J., and Hugouvieux-Cotte-Pattat, N. 1997. The pectate lyase PelI of Erwinia chrysanthemi belongs to a new family. J. Bacteriol. 179:7321-7330.

Simon, R., Priefer, U., and Pühler, A. 1983. A broad host range mobilization system for in vivo genetic engineering: Transposon mutagenesis in Gram-negative bacteria. Bio/Technology 1:784-791.

Simon, R., Quandt, J., and Klipp, W. 1989. New derivatives of trans- poson Tn5 suitable for mobilisation of replicons, generation of operon fusions and induction of genes in Gram-negative bacteria. Gene 80: 161-169.

Surgey, N., Robert-Baudouy, J., and Condemine, G. 1996. The Erwinia chrysanthemi pecT gene regulates pectinase gene expression. J. Bacteriol. 178:1593-1599.

Wacharotayankun, R., Arakawa, Y., Ohta, M., Hasegawa, T., Mori, M., Horii, T., and Kato, N. 1992. Involvement of $r c s B$ in Klebsiella K2 capsule synthesis in Escherichia coli K-12. J. Bacteriol. 174:1063-1067.

Yang, B. Y., Gray, J. S., and Montgomery, R. 1994. Extracellular polysaccharide of Erwinia chrysanthemi Ech6. Int. J. Biol. Macromol. 16: 306-312.

Yang, B. Y., Gray, J. S., and Montgomery, R. 1996. Comparison of extracellular polysaccharides of Erwinia chrysanthemi spp. Int. J. Biol. Macromol. 19:223-226. 